\title{
Measurements of Electric and Magnetic Fields Due to the Operation of Indoor Power Distribution Substations
}

\author{
Anastasia S. Safigianni, Member, IEEE, and Christina G. Tsompanidou
}

\begin{abstract}
In this paper, the electric and magnetic fields with a frequency of $50 \mathrm{~Hz}$, caused by the operation of indoor power distribution substations of $20 / 0.4 \mathrm{kV}$, are examined. First, the results of previous relevant research studies as well as the reference levels for safe general public and occupational exposure given in the guidelines of the International Commission on Non-Ionizing Radiation Protection are presented. Next, basic data for standardized indoor power distribution substations used in Greece, where the measurements have been carried out as well as a brief description of the field measurement instruments used are given. The results of the electric- and magnetic-field measurements in indoor power distribution substations of all the standardized nominal power ratings in the town of Xanthi, Greece, accompanied by relevant tables and diagrams follow. After the evaluation of these results, according to international guidelines, final conclusions are set out concerning safe public and occupational exposure to the above-mentioned fields.
\end{abstract}

Index Terms-Electric- and magnetic-field measurements, extremely low frequencies, indoor power distribution substations, safe public and occupational exposure.

\section{INTRODUCTION}

$\mathbf{E}$ XPOSURE to electromagnetic fields (EMFs) is not a new phenomenon. However, during the 20th century, environmental exposure to manmade EMFs has been steadily increasing as the growing demand for electricity, and ever-advancing technologies and changes in social behavior have created more and more artificial sources. While the enormous benefits of using electricity in everyday life and health care are unquestionable, during the past 20 years, the general public has become increasingly concerned about potential health hazards of exposure to electric and magnetic fields at extremely low frequencies (ELFs).

Since about 1980, these 50/60-Hz magnetic fields (and their frequency harmonics) have been suspected of causing various types of negative health effects. For instance, many people are concerned about the assumed relationship between the exposure to ELF EMFs and the increased risk of cancer. Internationally accepted scientific groups in [1]-[6] believe that the data are not sufficient to support the conclusion that power-frequency electric or magnetic fields in the workplace or at home cause cancer or lead to reproductive and developmental abnormalities or to learning and behavior problems. The most accurate

Manuscript received March 8, 2004; revised August 24, 2004. Paper no. TPWRD-00115-2004.

The authors are with the Electrical and Computer Engineering Department, Democritus University of Thrace, Xanthi GR-67100, Greece (e-mail: asafig@ee.duth.gr; xtsobanidou@ hotmail.com).

Digital Object Identifier 10.1109/TPWRD.2005.848659 answer to the question "do ELF EMFs present a human health hazard?" is that numerous studies around the world have failed to produce technically convincing evidence of such a hazard. Although some health effects have been statistically related to ELF EMFs exposure, these effects are poorly understood and may exist only as statistical or scientific errors. The expert working groups prepared a report [7] that evaluates possible health effects from exposure to static and ELF EMFs. The authors of [1], [8], and [9] identify gaps in knowledge that require more research to improve health risk assessments, including statistical, epidemiological, experimental, laboratory, and other studies.

Generally accepted guidelines have been established for safe public and occupational exposure to power-frequency EMFs. The reference levels for general public exposure to $50 / 60-\mathrm{Hz}$ electric and magnetic fields are, according to the ICNIRP guidelines [2] are as follows:

- for the electric field strength, $E<5 \mathrm{kV} / \mathrm{m}$;

- for the magnetic field strength, $H<80 \mathrm{~A} / \mathrm{m}$;

- for the magnetic flux density, $B<100 \mu \mathrm{T}$.

These levels for occupational exposure are:

- for the electric field strength, $E<10 \mathrm{kV} / \mathrm{m}$;

- for the magnetic field strength, $H<400 \mathrm{~A} / \mathrm{m}$;

- for the magnetic flux density, $B<500 \mu \mathrm{T}$.

Various researchers have treated, at great length, the measurement and model elaboration for the determination of the electric and magnetic fields generated by transmission lines, particularly by lines that cross residential areas. Other researchers have considered it convenient to characterize the EMF inside residences. But there is little data available in the literature dealing with EMF measurements and calculations in power stations and substations of various voltage levels. Specifically in [10], measurements of magnetic-field profiles around a specific substation have verified that adding a substation under an existing transmission line does not increase the magnetic field beyond the substation boundary. In [11], magnetic fields in a $187 / 66-\mathrm{kV}$ substation are calculated for various current conditions and described in terms of contour plots. In [12], the magnetic fields generated by a distribution substation were measured and calculated, based on a computer model that takes into account currents in the grounding systems, distribution feeder neutrals, overhead ground wires, and induced currents in equipment structures and ground grid loops. In [13], measurements of the field strength in a combined cycle gas turbine power station are described, for both the steady-state situation and the process of starting the generator. The measurement results are compared to the established safe exposure limits. In 
[14], an integral approach method is used for magnetic-field measurements in a $69-\mathrm{kV}$ SF6 gas-insulated substation in Taiwan. Reference [15] shows the results of an initial series of measurements carried out to determine the levels of EMFs in various indoor and outdoor environments (power transmission lines, power cables, substations, domestic electrical equipment) associated with occupational and residential exposure. Finally, in [16] and [17], shielding is proposed for an in-house secondary substation in Sweden in order to mitigate the magnetic field. This shielding really reduces the field values compared to the values measured before the shielding installation. We must, however, point out that these values are already far below today's accepted safe exposure limits.

This paper examines the ELF fields caused by the operation of indoor power distribution substations $20 / 0.4 \mathrm{kV}$. The number of substations and their close proximity to homes and workplaces causes anxiety among people over possible health hazards from the resultant electric and magnetic fields. So, first, basic data are given for standardized indoor power distribution substations used in Greece, where the field measurements were made, and a brief description of the instruments used to make the measurements is provided. Indicative results, accompanied by relevant tables and diagrams, follow for the electric- and magnetic-field measurements in an indoor power distribution substation of nominal power $2 \times 630 \mathrm{kVA}$ in the town of Xanthi, Greece. The results of relative measurements in all of the types of standardized indoor power distribution substations are evaluated according to international guidelines. Final conclusions are set out concerning safe public and occupational exposure to electric and magnetic fields caused by the operation of such substations.

\section{INDOOR POWER DISTRIBUTION SUBSTATIONS}

In cities where many buildings are in close proximity to each other, the load density is high. Therefore, indoor power distribution substations, which usually have high nominal power, are located in the basement or the ground floor of buildings. It is easy to find such rooms in buildings. However, where the load density is small, such as in regional areas close to a city, pole-type power distribution transformers are used. Even when a cheap indoor room is available, it is preferable, in the second case, to divide the load between more than one pole-type substation instead of installing one big indoor power distribution substation in order to satisfy the "effective protective earthing condition." According to this condition, when a solid phase-to-neutral short-circuit occurs anywhere in the external network or in the consumer installation, the system protective devices have to interrupt the power supply within a finite time. This applies to low-voltage networks with the equipment frames connected to the neutral conductor. It protects people from dangerous touch voltages as determined in [18].

From an economic viewpoint, the real-estate purchase for the installation of an indoor power distribution substation is directly comparable to the cost of the two-pole construction needed in the case of a pole-type substation. But an indoor substation is burdened in addition with the costs of arranging the installation room (construction work, channels, doors, ventilation grids, etc.) and the costs of the requisite work (contract work cost and cost for the underground network materials). In conclusion, for technical and aesthetic reasons as well as the impossibility of finding a place for a pole-type substation, there is often no option but to construct indoor power distribution substations within cities.

The standardized indoor power distribution substations of the Public Power Corporation (PPC) in Greece have nominal powers of 250, 400, 630, $2 \times 400,2 \times 630$, and $1000 \mathrm{kVA}$. Their number is significant. For example in the town of Xanthi, which has 50000 inhabitants, 52 such substations are installed. Their number and their close proximity to house and workplaces justify the concern of the town inhabitants over the health hazards from the fields caused by the operation of these substations.

\section{EleCtRIC- AND MAGNETIC-FIELD MEASUREMENTS}

One of the instruments that can be used for the measurement of low-frequency magnetic and electric fields in the frequency range $5 \mathrm{~Hz}$ to $30 \mathrm{kHz}$ is the EFA-3 analyzer. The analyzer, constructed by the Wandel and Goltermann Company, supports recording, storage, and evaluation functions for sequences of results and can measure electric and magnetic fields. Its characteristics are the following:

- isotropic magnetic field probe built-in;

- omnidirectional (isotropic) measurements;

- measurement ranges from $5 \mathrm{nT}$ to $10 \mathrm{mT}, 0.1 \mathrm{mG}$ to $100 \mathrm{G}$, and $0.1 \mathrm{~V} / \mathrm{m}$ to $100 \mathrm{kV} / \mathrm{m}$;

- true root-mean-square (rms) or peak value measurement;

- spectral detection of field components;

- built-in frequency counter;

- preset table audible and visible alarm thresholds;

- user-definable filter frequency;

- timer-controlled recording of results;

- calibrated;

- external electric- and magnetic-field probes.

The measurements were carried out using the three-dimensional (3-D) isotropic probe that ensures omnidirectional measurements. The EFA-3 analyzer has the capability of storing 4000 result values. These values can then be output via the built-in printer interface directly to a printer or clearly displayed on a PC fitted with appropriate software. Long-term measurements lasting up to $24 \mathrm{~h}$ can be performed easily using the timer-controlled recording function.

One indoor power distribution substation of each standardized nominal power found in the town of Xanthi (i.e., 250, 400, $630,2 \times 400$, and $2 \times 630 \mathrm{kVA}$ ), was selected in order to measure the electric and magnetic field in the context of this paper. This selection is sufficient because the dimensions of the room, where such a substation is installed and the equipment arrangements, are about the same (standardized by the PPC) for the indoor power distribution substations of all the standardized nominal power ratings. Bigger rooms are provided for the substations with two instead of one transformer. All of the substation rooms are naturally ventilated and far from any other equipment using high amounts of power, such as air conditioning units, elevator motors, etc. As a consequence, the measured field values are affected only by the substation load and not by the substation room configuration. Fig. 1 shows the ground plan sketch of a $2 \times 630$ $\mathrm{kVA}$ power distribution substation room. The dimensions of the floor surface are about $5.5 \times 13.5 \mathrm{~m}$. The origin of the axes $\mathrm{x}$, 
TABLE I

Magnetic Flux Density Values in a $2 \times 630$ kVA Power Distribution Substation Room

\begin{tabular}{|c|c|c|c|c|c|c|c|c|c|c|c|}
\hline \multirow[b]{2}{*}{$\begin{array}{l}\text { Measurement } \\
\text { position }\end{array}$} & \multicolumn{2}{|c|}{$\begin{array}{l}\text { Distance from the } \\
\text { axis origin, }(\mathrm{m})\end{array}$} & \multicolumn{3}{|c|}{$\begin{array}{c}\text { rms magnetic flux density } \\
\text { values } B,(\mu \mathrm{T})\end{array}$} & \multirow[b]{2}{*}{$\begin{array}{l}\text { Measurement } \\
\text { position }\end{array}$} & \multicolumn{2}{|c|}{$\begin{array}{l}\text { Distance from the } \\
\text { axis origin, }(m)\end{array}$} & \multicolumn{3}{|c|}{$\begin{array}{c}\text { rms magnetic flux density } \\
\text { values } B,(\mu \mathrm{T})\end{array}$} \\
\hline & $x$ & $y$ & Head & Waist & Floor & & $x$ & $y$ & Head & Waist & Floor \\
\hline M1 & 3.10 & 10.30 & 14 & 19 & 24 & M38 & 0.00 & 8.50 & 3 & 3 & 7 \\
\hline M2 & 3.10 & 9.45 & 6 & 8 & 16 & M39 & 0.00 & 7.60 & 2 & 2 & 5 \\
\hline M3 & 3.10 & 8.60 & 4 & 5 & 15 & M40 & 0.00 & 6.75 & 3 & 5 & 7 \\
\hline M4 & 3.10 & 7.80 & 4 & 5 & 12 & M41 & 0.00 & 5.90 & 5 & 6 & 7 \\
\hline M5 & 3.10 & 7.05 & 10 & 18 & 15 & M42 & 0.00 & 5.00 & 3 & 3 & 4 \\
\hline M6 & 2.40 & 7.05 & 22 & 35 & 33 & $\mathrm{~K} 1$ & 0.70 & 0.00 & 18 & 24 & 23 \\
\hline M7 & 2.40 & 7.80 & 5 & 9 & 35 & $\mathbf{K} 2$ & 0.70 & 0.80 & 59 & 81 & 105 \\
\hline M8 & 2.40 & 8.60 & 6 & 9 & 42 & K3 & 0.70 & 1.60 & 144 & 24 & 54 \\
\hline M9 & 2.40 & 9.45 & 11 & 16 & 53 & $\mathrm{~K} 4$ & 0.70 & 2.40 & 20 & 32 & 23 \\
\hline M10 & 2.40 & 10.30 & 51 & 74 & 113 & K5 & 0.70 & 3.20 & 38 & 108 & 46 \\
\hline M11 & 2.70 & 12.45 & 38 & 26 & 24 & K6 & 0.70 & 3.95 & 9 & 17 & 30 \\
\hline M12 & 1.75 & 12.95 & 7 & 9 & 9 & K7 & 0.70 & 4.75 & 4 & 5 & 6 \\
\hline M13 & 1.75 & 12.10 & 18 & 25 & 32 & K8 & 1.50 & 4.75 & 3 & 4 & 29 \\
\hline M14 & 1.75 & 11.30 & 101 & 148 & 334 & K9 & 1.50 & 3.95 & 5 & 8 & 31 \\
\hline M15 & 1.75 & 10.50 & 157 & 244 & 197 & K10 & 1.50 & 3.20 & 13 & 23 & 26 \\
\hline M16 & 1.75 & 9.70 & 17 & 24 & 48 & K11 & 1.50 & 2.40 & 9 & 14 & 21 \\
\hline M17 & 1.75 & 8.90 & 5 & 9 & 43 & K12 & 1.50 & 1.60 & 19 & 24 & 31 \\
\hline M18 & 1.75 & 8.10 & 4 & 7 & 36 & K13 & 1.50 & 0.80 & 19 & 24 & 28 \\
\hline M19 & 1.75 & 7.30 & 9 & 14 & 34 & K14 & 1.50 & 0.00 & 10 & 13 & 12 \\
\hline M20 & 1.75 & 6.50 & 49 & 67 & 67 & K15 & 2.30 & 0.00 & 4 & 4 & 4 \\
\hline M21 & 1.75 & 5.70 & 307 & 429 & 164 & K16 & 2.30 & 0.80 & 5 & 5 & 5 \\
\hline M22 & 1.75 & 5.00 & 18 & 21 & 49 & K17 & 2.30 & 1.60 & 5 & 6 & 7 \\
\hline M23 & 0.80 & 5.00 & 6 & 8 & 10 & K18 & 2.30 & 2.40 & 4 & 5 & 7 \\
\hline M24 & 0.80 & 5.90 & 13 & 16 & 14 & K19 & 2.30 & 3.20 & 4 & 5 & 20 \\
\hline M25 & 0.80 & 6.75 & 8 & 10 & 14 & K20 & 2.30 & 3.95 & 2 & 3 & 36 \\
\hline M26 & 0.80 & 7.60 & 3 & 3 & 6 & K21 & 2.30 & 4.75 & 4 & 6 & 21 \\
\hline M27 & 0.80 & 8.50 & 3 & 4 & 11 & K22 & 3.00 & 4.75 & 15 & 17 & 15 \\
\hline M28 & 0.80 & 9.35 & 5 & 6 & 12 & K23 & 3.00 & 3.95 & 6 & 6 & 8 \\
\hline M29 & 0.80 & 10.25 & 16 & 23 & 25 & K24 & 3.00 & 3.20 & 2 & 3 & 6 \\
\hline M30 & 0.80 & 11.15 & 22 & 32 & 45 & K25 & 3.30 & 2.40 & 2 & 2 & 3 \\
\hline M31 & 0.80 & 12.05 & 10 & 13 & 19 & K26 & 3.30 & 1.60 & 2 & 2 & 3 \\
\hline M32 & 0.80 & 12.95 & 7 & 7 & 8 & K27 & 3.30 & 0.80 & 2 & 2 & 2 \\
\hline M33 & 0.00 & 12.95 & 5 & 6 & 7 & K28 & 3.30 & 0.00 & 2 & 2 & 2 \\
\hline M34 & 0.00 & 12.05 & 7 & 9 & 12 & K29 & 4.50 & 0.00 & 1 & 1 & 1 \\
\hline M35 & 0.00 & 11.15 & 10 & 13 & 16 & K30 & 4.50 & 0.80 & 2 & 2 & 2 \\
\hline M36 & 0.00 & 10.25 & 7 & 8 & 11 & K31 & 4.50 & 1.60 & 5 & 4 & 4 \\
\hline M37 & 0.00 & 9.35 & 4 & 5 & 7 & K32 & 4.50 & 2.40 & 3 & 3 & 4 \\
\hline
\end{tabular}

$\mathrm{y}$ and the successive positions, where the measuring instrument was placed, are marked in Fig. 1. The selected substation is installed in the basement of a multistory building in the town center and supplies about 1500 of the town's 31800 consumers.

In Table I, the positions of the measurement instrument are registered, as well as the distance of these positions from the axis origin and the measured magnetic flux density values (rms values in $\mu$ icroTesla). The measurement positions $\mathrm{Mx}$, where $\mathrm{x}$ is the location number as shown in Fig. 1, are in the transformer room. The measurement positions $\mathrm{Kx}$ are inside the room for the switchboards and the distribution fuse boxes. Three measurements correspond to each position. The first one refers to a head height $(1.80 \mathrm{~m})$, the second to a waist height $(1 \mathrm{~m})$, and the third to the floor surface. The stability of the measurement height was obtained by using a special wooden support stand, where the measuring instrument can be placed at successive positions that are $30 \mathrm{~cm}$ apart, from the floor surface to a height of $2 \mathrm{~m}$. All of the measurements were carried out at $50 \mathrm{~Hz}$.

Diagrams are given in Fig. 2 showing contour and surface maps for the magnetic flux density at a waist height based on the values in Table I. The diagrams for head and floor heights are relative. Positions, where measurements were impossible, have been excluded from the above diagrams. The diagrams have been plotted taking into account the reference levels for safe occupational exposure, because only the PPC technicians can enter the substation room. Access to the public is forbidden.

Apart from the magnetic flux density, the electric-field strength was measured inside the power distribution substation 


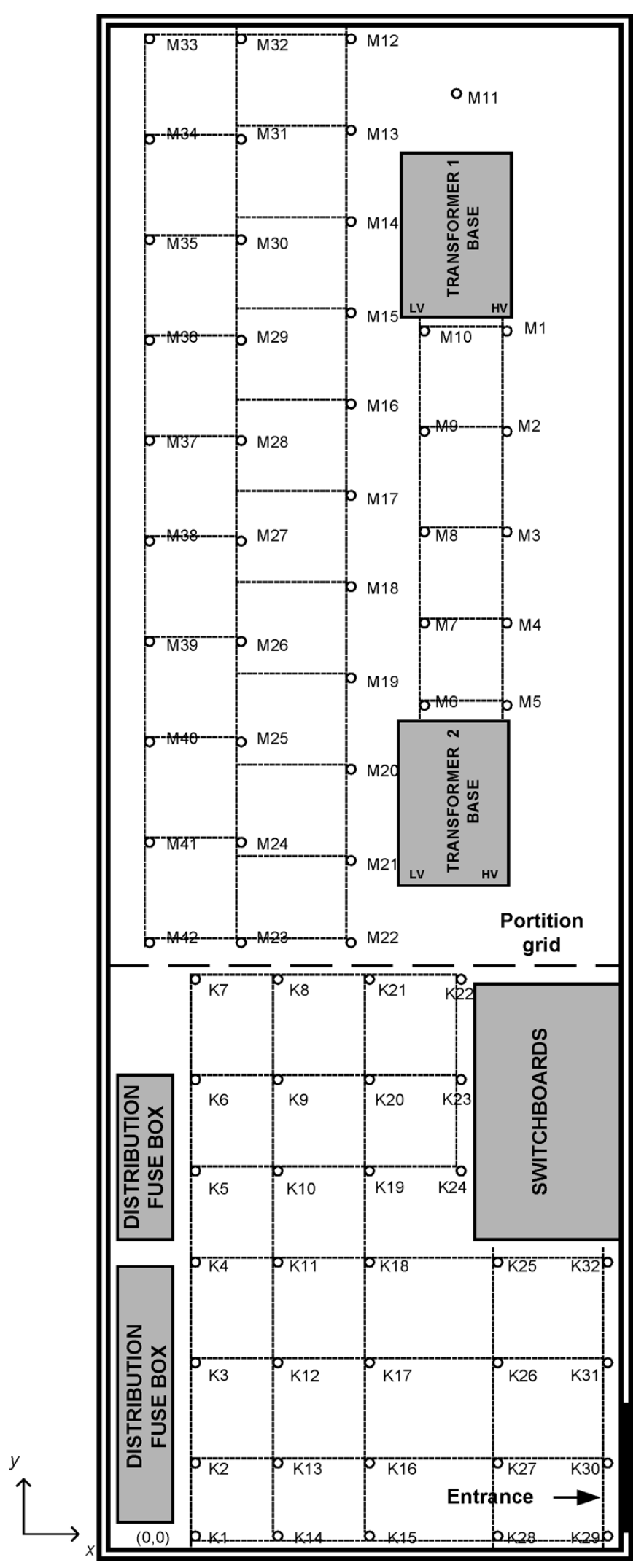

Fig. 1. Ground plan sketch of an indoor $2 \times 630 \mathrm{kVA}$ power distribution substation room. $\mathrm{M}_{\mathrm{i}}, \mathrm{K}_{\mathrm{i}}$ : measurement positions.

room with the doors of the distribution fuse boxes open. The electric-field sensor was placed at the measurement positions and connected to the main instrument with a 10 -m fiber-optic cable. This connection and the distance between the sensor and the main instrument were necessary in order to ensure that the electric-field strength would not be perturbed by the presence of people. In the transformer room, the measured electric-field strength at the frequency of $50 \mathrm{~Hz}$ did not exceed $3 \mathrm{~V} / \mathrm{m}$. The maximum electric-field strength in the switchboards and the distribution fuse boxes room, at the same frequency, was $2 \mathrm{~V} / \mathrm{m}$.

During the field measurements, the three-phase currents at the low-voltage side of each transformer were also recorded. At the low-voltage side of transformer 1, the three-phase currents were $I_{1 \mathrm{a}}=670 \mathrm{~A}, I_{1 \mathrm{~b}}=760 \mathrm{~A}, I_{1 \mathrm{c}}=640 \mathrm{~A}$. The relative currents of transformer 2 were $I_{2 \mathrm{a}}=635 \mathrm{~A}, I_{2 \mathrm{~b}}=$ $590 \mathrm{~A}, I_{2 \mathrm{c}}=600 \mathrm{~A}$. Consequently, the maximum phase currents for each transformer were, respectively, $I_{1 \max }=760 \mathrm{~A}$ and $I_{2 \max }=635 \mathrm{~A}$.

The nominal current of a 630-kVA transformer is

$$
I_{\mathrm{n}}=\frac{S}{\sqrt{3} \times U}=\frac{630 \mathrm{kVA}}{\sqrt{3} \times 0.4 \mathrm{kV}}=909.33 \mathrm{~A}
$$

where $S$ is the nominal power of the transformer and $U$ is the line-to-line nominal voltage.

The ratio of the maximum measured to the nominal current of transformer 1 is, according to the following:

$$
\frac{I_{1 \max }}{I_{\mathrm{n}}}=\frac{760 \mathrm{~A}}{909.33 \mathrm{~A}}=0.836 \text { i.e. } I_{\mathrm{n}}=1.196 I_{1 \max } .
$$

The same ratio for transformer 2 is

$$
\frac{I_{2 \max }}{I_{\mathrm{n}}}=\frac{635 \mathrm{~A}}{909.33 \mathrm{~A}}=0.698 \text { i.e. } I_{\mathrm{n}}=1.433 I_{2 \max } .
$$

\section{Evaluation of the Measurement Results}

In the $2 \times 630 \mathrm{kVA}$ indoor substation during the measurements, transformer 1 operated under $83.6 \%$ of the nominal load while transformer 2 operated under $69.8 \%$ of the nominal load.

In the transformer room, the magnetic-field reference level for the public $(100 \mu \mathrm{T})$ was exceeded in four positions (M10, M14, M15, and M21, with bold letters in Table I). Three of these positions were at the low-voltage side of transformer 1 while the fourth was at the low-voltage side of transformer 2. In the switchboards-distribution fuse boxes room, the magnetic-field reference level for the public was exceeded in three positions in front of the distribution fuse boxes (K2, K3, and $\mathrm{K} 5$, with bold letters in Table I).

Measurements inside other standardized power distribution substation rooms have given similar results. The maximum measured currents and magnetic flux density values inside the substation rooms as well as the magnetic flux density value for every standardized transformer, extrapolated to the nominal transformer power, are given in Table II. This extrapolation was made giving due consideration to the fact that the magnetic flux density variation is proportional to the relative current variation.

It should be clarified that the maximum measured current $I_{\max }$ in the case of substations with two transformers $(2 \times$ $630 \mathrm{kVA}$ or $2 \times 400 \mathrm{kVA}$ substations) according to Table II corresponds to the load of one of these transformers only. Specifically, this is the current of the transformer closest to which the 

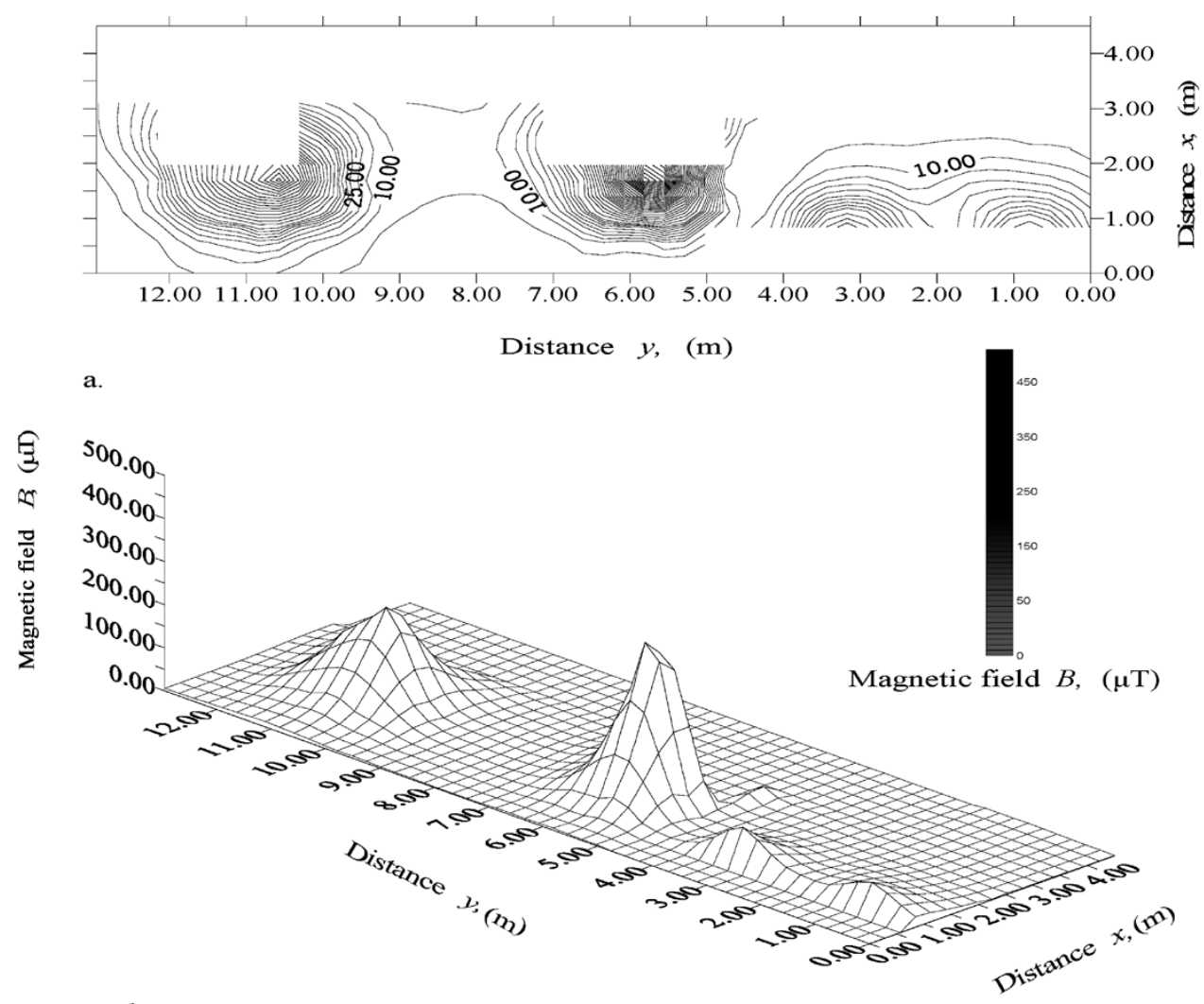

b.

Fig. 2. Magnetic flux density distribution at a waist height in a $2 \times 630 \mathrm{kVA}$ power distribution substation room. (a) Contour map. (b) Surface map.

TABLE II

CURRENT AND Magnetic Flux Density Values Inside Standardized INDOOR POWER DISTRIBUTION SUBSTATION ROOMS

\begin{tabular}{c|c|c|c|c}
\hline $\begin{array}{c}\text { Nominal } \\
\text { substation } \\
\text { power } S_{\mathrm{n}} \\
(\mathrm{kVA})\end{array}$ & $\begin{array}{c}\text { Maximum } \\
\text { measured } \\
\text { current } I_{\max }, \\
(\mathrm{A})\end{array}$ & $\begin{array}{c}\text { Maximum } \\
\text { measured } \\
\text { magnetic } \\
\text { flux density } \\
\text { values } B_{\max }, \\
(\mu \mathrm{T})\end{array}$ & $\begin{array}{c}\text { Ratio of the } \\
\text { nominal } \\
\text { current to } \\
\text { the } \\
\text { maximum } \\
\text { measured } \\
\text { current, } \\
I_{\mathrm{n}} / I_{\max }\end{array}$ & $\begin{array}{c}\text { Magnetic } \\
\text { flux density } \\
\text { value } \\
\text { extrapolated } \\
\text { to the } \\
\text { nominal } \\
\text { power, }(\mu \mathrm{T})\end{array}$ \\
\hline 250 & 82 & 24 & 4.4 & 106 \\
\hline 400 & 250 & 81 & 2.3 & 186 \\
\hline 630 & 370 & 466 & 2.45 & 1142 \\
\hline $2 \times 400$ & 280 & 255 & 2.1 & 536 \\
\hline $2 \times 630$ & 760 & 429 & 1.2 & 515 \\
\hline
\end{tabular}

maximum magnetic flux density value was measured. The current of the second transformer of the substation is approximately the same, but smaller.

No serious differentiation was noted in the measured magnetic flux density values in relation to the body height. Therefore, no clear conclusion can be drawn about the body height (head, waist, floor) where the field is stronger.

No excessive magnetic-field reference level for safe occupational exposure $(500 \mu \mathrm{T})$ was noted during the measurements, either in the transformers room or in the switchboards-distribution fuse boxes room. Marginal excess has resulted in the extrapolation of the measured magnetic flux density values for the actual transformer loads to their nominal power, as Table II shows. But power distribution transformers rarely operate at their nominal power. If this happens, such operation is fleeting and, therefore, the above excess is not alarming.

Additional measurements taken at public-access places have shown magnetic flux density values to be much lower than the reference level for safe public exposure (building entrance 0.8 $\mu \mathrm{T}$, ventilation grid on the pavement $0.8 \mu \mathrm{T}$, feed pole $0.9 \mu \mathrm{T}$, at the water and electricity meters $1.5 \mu \mathrm{T}$ ). Public access to the substation rooms is prohibited. Only the PPC technicians have access to these rooms, where they are not required to spend much time. During repairs or scheduled maintenance, which demand lengthy procedures, the substation is not under voltage and so no field exists. Guidelines suggest that the measured magnetic flux density values are not dangerous and, therefore, are no cause for concern.

The electric-field strengths measured inside all of the substations were far below the relative reference level for safe public exposure $(5 \mathrm{kV} / \mathrm{m})$.

The relatively high magnetic flux density values in positions that are in very close proximity to the transformers or to the distribution fuse boxes (for instance, the value $466 \mu \mathrm{T}$ within the 630-kVA substation, although it has a load smaller than half of its nominal load) can be justified by several factors. These include: 1) the asymmetry in the values of the three phase currents; 2 ) the space asymmetry of the phase conductors (conductors placed in a flat plane and not at the vertices of an equilateral triangle); 3) the asymmetrical position of the measuring instrument with reference to the three-phase conductors; and 4) the small distances between this instrument and the phase conductors, etc. 


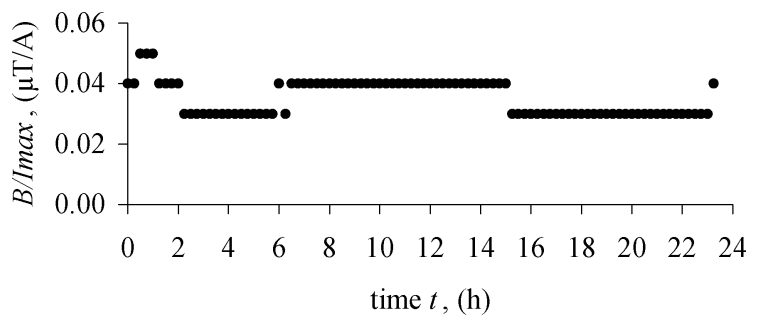

Fig. 3. Diurnal variation of the $B / I_{1}$ max ratio in a random position of a $2 \times$ $630 \mathrm{kVA}$ power distribution substation room.

In order to ascertain whether the extrapolation of the measured magnetic flux density values to the nominal transformer power, which preceded and is recorded in Table II, was reliable, an additional measurement has been carried out for the purpose of determining the exact relation between the magnetic flux density and the current. Specifically, in the $2 \times 630 \mathrm{kVA}$ indoor power distribution substation, which has measured magnetic flux density values higher than those of the other substations because of the higher currents, the magnetic-field analyzer was placed at position M13 in front of transformer 1 and at waist height. It was programmed to measure the magnetic flux density every $15 \mathrm{~min}$ for $24 \mathrm{~h}$. At similar intervals, the values of the currents flowing through the three phases on the low-voltage side of the transformer were recorded. From these records, the three phases were unequally loaded but without great imbalances. Fig. 3 shows that for currents between 210 and $620 \mathrm{~A}$, a typical diurnal variation, the magnetic field was proportional to the current with the constant of proportionality $B / I_{1 \text { max }}$ being $0.04+/-0.01 \mu \mathrm{T} / \mathrm{A}$.

\section{CONCLUSION}

In recent years, as the demand for electricity has steadily increased, the general public and working personnel have become increasingly concerned about the health hazards of exposure to ELF EMFs. National and international guidelines have enacted reference levels for safe exposure, while researchers from different areas of expertise deal with the above-mentioned health effects.

This paper reports the results of electric- and magnetic-field measurements within indoor power distribution substations. The measurements were made to determine whether internationally accepted reference levels for safe exposure were violated. Both these measurements and the elaboration of the relevant results show that the magnitudes of the measured field values are within recognized guidelines, suggesting that the fields are not dangerous and, therefore, are no cause for concern among the public or working personnel.

\section{REFERENCES}

[1] "Possible health hazards from exposure to power-frequency electric and magnetic fields-A COMAR technical information statement," IEEE Eng. Med. Biol., vol. 19, no. 1, pp. 131-137, Jan./Feb. 2000.

[2] International Commission of Non Ionizing Radiation Protection (ICNIRP), "Guidelines for limiting exposure to time-varying electric, magnetic and electromagnetic fields (up to $300 \mathrm{GHz}$ )," Health Phys., vol. 74, no. 4, pp. 494-522, Apr. 1998.

[3] Australian Radiation Protection And Nuclear Safety Agency. (2003, Jun.) Electricity and Health. [Online] Available: http://www.arpansa. gov.au/is_electricity.htm
[4] National Research Council, USA, Possible health effects of exposure to residential electric and magnetic fields, Nation Academy Press, Washington, DC, 1997.

[5] National Research Council, USA, Research on power-frequency fields under the energy policy act of 1992, Nat. Acad. Press, Washington, DC, 1999.

[6] "Power-frequency electromagnetic fields and health, on behalf of the technical committee," Electra, p. 196, Jun. 2001.

[7] M. H. Repacholi and B. Greenebaum, "Interaction of static and extremely low frequency electric and magnetic fields with living systems: Health effects and research needs," Bioelectromagn., vol. 20, no. 3, pp. 133-160, 1999.

[8] A. W. Preece, J. W. Hand, R. N. Clarke, and A. Stewart, "Power frequency electromagnetic fields and health. Where's the evidence?," Phys Med. Biol., vol. 45, no. 9, pp. 139-154, 2000.

[9] R. T. Hitchcock and R. M. Patterson, Radio-Frequency and ELF Electromagnetic Energies. A Handbook for Health Professionals. New York: Van Nostrand, 1995.

[10] W. E. Feero, J. Yontz, and J. H. Dunlap, "Magnetic fields remote from substations," IEEE Trans. Power Del., vol. 4, no. 3, pp. 1862-1868, Jul. 1989.

[11] L. Hayashi, K. Isaka, and Y. Yokoi, "Analysis of 60-Hz magnetic fields near ground level in 187-kV switchyard of a 187/66-kV AC substation," IEEE Trans. Power Del., vol. 7, no. 1, pp. 237-243, Jan. 1992.

[12] W. K. Daily and F. Dawalibi, "Measurements and calculations of electromagnetic fields in electric power substations," IEEE Trans. Power Del., vol. 9, no. 1, pp. 324-333, Jan. 1994.

[13] B. Jaekel, "Low frequency magnetic fields near energized components of power stations," in Proc. Int. Wroclaw Symp. Electromagnetic Compatibility, Wroclaw, Poland, 1998, pp. 133-137.

[14] L. Shun-Li, L. E. Ghin, L. E. Ching-Lien, and H. T.-C. Lu, "Power substation magnetic field measurement using digital signal processing techniques," IEEE Trans. Power Del., vol. 14, no. 4, pp. 1221-1227, Oct. 1999.

[15] A. S. Farag, M. M. Dawoud, T. C. Cheng, and J. S. Cheng, "Occupational exposure assessment for power frequency electromagnetic fields," Elect. Power Syst. Res., vol. 48, pp. 151-175, 1999.

[16] E. Salinas, L. Aspemyr, J. Daalder, Y. Hamnerius, and J. Luomi, "Power frequency magnetic fields from in-house secondary substations," in Proc. Conf. Electricity Distribution, Nice, France, 1999, pp. 161-164.

[17] E. Salinas, "Magnetic field management at the transmission and distribution stages," in Proc. 5th Int. Power Engineering Conf., Singapore, 2001, pp. 325-330.

[18] VDE Recommendation to the Calculation of Short-Circuit Currents Part 1. Three Phase Installations With Rated Voltages up to $1000 \mathrm{~V}$. Berlin, Germany: VDE-Verlag, 1985.

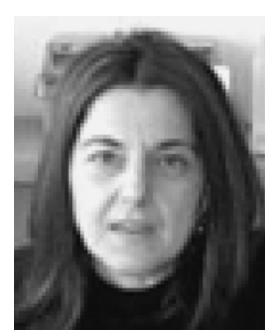

Anastasia S. Safigianni (M'97) was born in Trikala, Greece, in 1957. She received the Dipl.-Eng. and $\mathrm{Ph} . \mathrm{D}$. degrees in electrical engineering from the Electrical Engineering Department, Democritus University of Thrace, Xanthi, Greece, in 1981 and 1988, respectively.

Currently, she is an Associate Professor in the Electrical and Computer Engineering Department, Democritus University of Thrace. Her teaching interests include power systems and electrical installations. Her research interests include power systems planning and optimization, short-circuit losses and forces in metal enclosed arrangements, and the influence of extra low-frequency electric and magnetic fields on human beings.

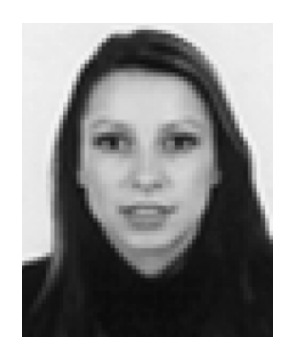

Christina G. Tsompanidou was born in Komotini, Greece, in 1978. She received the Dipl-Eng. degree in electrical engineering in 2002 from the Electrical and Computer Engineering Department of the Democritus University of Thrace, Xanthi, Greece, where she is currently pursuing the M.Sc. degree in the Electrical and Computer Engineering Department, Democritus University of Thrace.

Her research interests include the influence of extra low-frequency electric and magnetic fields on human beings. 